\title{
SOSIOLOGI SASTRA TOKOH UTAMA DALAM NOVEL PETUALANGAN TOM SAWYER KARYA MARK TWAIN
}

\author{
Imas Juidah \\ Program Studi Pendidikan Bahasa dan Sastra Indonesia \\ Universitas Wiralodra
}

Email: imas.juidah@unwir.ac.id

\begin{abstract}
ABSTRAK
Tujuan yang akan dicapai penulis dalam penelitian ini, yaitu (1) mendeskripsikan struktur intrinsik novel Petualangan Tom Sawyer karya Mark Twain dan (2) mendeskripsikan aspek sosiologi sastra tokoh utama novel Petualangan Tom Sawyer karya Mark Twain. Data dalam penelitian ini kata-kata, kalimat, dan kutipan yang terdapat dalam novel Petualangan Tom Sawyer. Sumber data primer berupa novel Petualangan Tom Sawyer karya Mark Twain diterbitkan oleh Penerbit Narasi Yogyakarta, dengan tebal 412 halaman. Sumber data sekunder berupa buku-buku acuan tentang teori sastra, teori sosiologi, artikel-artikel dari internet, dan novel Petualangan Tom Sawyer karya Mark Twain. Teknik pengumpulan data menggunakan teknik simak catat. Teknik analisis data menggunakan metode Content Analysis atau teknik analisis isi. Tokoh utama dalam novel Petualangan Tom Sawyer adalah Tom Sawyer. Dari pembahasan data, penulis memperoleh kesimpulan bahwa aspek sosiologi sastra tokoh utama dalam novel Petualangan Tom Sawyer karya Mark Twain dari sudut pandang sosiologi sastra yaitu aspek moral dalam hal ini yang diungkap adalah perbuatan, sikap, budi pekerti, susila para tokoh utama; aspek etika membahas tentang kesusilaan yang menentukan tentang bagaimana manusia hidup dalam masyarakat; aspek sosial ekonomi terbagi atas tiga golongan (1) golongan ekonomi rendah, (2) golongan ekonomi menengah, (3) golongan ekonomi atas; aspek cinta kasih membahas hubungan rasa cinta kasih antara Tom Sawyer dan Becky Tathcher ; aspek agama yang terdapat dalam novel Petualangan Tom sawyer adalah seorang anak yang diwajibkan untuk beribadah kepada tuhan; aspek pendidikan yang ditampilkan mencakup pendidikan formal dan pendidikan dalam keluarga dan masyarakat.
\end{abstract}

Kata Kunci: Sosiologi, Moral, Etika, Sosial, Agama, dan Pendidikan. 


\section{PENDAHULUAN}

Novel Petualangan Tom Sawyer karya Mark Twain ini mengisahkan tentang lika-liku petualangan Tom Sawyer dan Huckleberry Finn dalam mencari harta karun. Yang menjadikan novel ini menarik dikarenakan kecerdasan Mark Twain dalam memainkan alur cerita dan emosi pembaca. Lebih jelasnya secara singkat dapat penulis kemukakan mengenai alasan penelitian ini, yaitu bahwa novel Petualangan Tom Sawyer karya Mark Twain merupakan karya sastra yang mengandung pesan moral terutama melalui tokoh utamanya Tom Sawyer dan Hucklebbry Finn. Mereka memiliki kecerdasan, keuletan untuk mencapai keinginan serta menjalani kehidupannya yang menyenangkan, bergitu pula kisah tentang perjalanan mereka yang ingin menjadi seorang 'penyamun', meskipun mereka banyak menghadapi permasalahan dalam perjalanan mereka dan konflik-konflik yang muncul karena ulah mereka dalam petualangan yang dilakukan. Novel Petualangan Tom Sawyer karya Mark Twain menarik diteliti dari segi sosiologi terutama tokoh utamanya, yang penulis anggap cukup representatif dari keseluruhan tokoh yang ada dalam novel Petualangan Tom Sawyer karya Mark Twain. Novel Petualangan karya Mark Twain ini menurut penulis akan menambah perbendaharaan kasusastraan Indonesia yang layak dicatat dan mendapatkan tempat di kalangan pencintanya. Dengan demikian judul yang penulis ajukan dalam penelitian ini "Kajian Sosiologi Sastra Tokoh Utama Dalam Novel Petualangan Tom Twain Karya Mark Twain”.

Novel Petualangan Tom Sawyer karya Mark Twain adalah satu novel terjemahan yang diterbitkan oleh Penerbit Narasi Yogyakarta, pada Tahun 2007 dengan tebal sebanyak 412 halaman. Novel Petualangan Tom Sawyer karya Mark Twain adalah novel yang menceritakan tentang petualangan anak-anak untuk mencari harta karun dan kesenangan yang diinginkan oleh anak-anak. Tokoh utama dalam novel ini adalah Tom Sawyer yang merupakan anak yang cerdas, dibandingkan dengan teman-temannya. Tom adalah anak yang bandel bahkan dia dicap sebagai 'Brandal' baik itu di sekolah maupun di masyarakat. Tom tidak memiliki orang tua lagi dan dia diasuh oleh Bibinya yaitu Bibi Polly. Tom terenal anak yang nakal hingga kerap kali dia mendapat hukuman disekolahnya karena sering tidak masuk sekolah untuk berenang di sungai, rotan dan cambukan pun memjadi hadiahnya. Huckleberry Finn adalah sahabat Tom dan menuruti perintah Tom. Huckleberry Finn terkeSeperti layaknya anak-anak seusianya, Tom dan Huckleberry gemar berkhayal melakukan hal-hal yang besar. Bersama dengan sahabatnya, Huckleberry Finn, ia mencoba lari dari rutinitas kehidupan yang 
membosankan untuk menjadi 'penyamun'.

Dari kenakalan mereka telah membawa keduanya berurusan dengan Inyun Joe, pembunuh dr. Robinson, yang pada akhirnya justru menggiring mereka pada pemburuan harta karun yang mendebarkan.

\section{KAJIAN TEORI}

1. Sastra

a. Pengertian Sastra

Secara etimologis, kata sastra dalam bahasa Indonesia (dalam bahasa Inggris sering disebut literature dan berasal dari bahasa Sansekerta: akar kata sas-, dalam kata kerja turunan berarti "mengarahkan, mengajar, memberi petunjuk atau instruksi”. Akhiran -tra, biasanya menunjukkan "alat, sarana". Jadi sastra dapat berarti "alat untuk mengajar, buku petunjuk, buku instruksi, atau pengajaran" (Endraswara, 2008: 4).

b. Struktur Sastra

Menurut Baribin (1985: 52) unsur pembangun fiksi terdiri dari tema, tokoh dan penokohan, alur atau plot, latar, gaya bahasa, pusat pengisahan. Unsur cerkaan yang terpenting adalah alur, penokohan, latar, dan pusat pengisahan. a. Pengertian Sosiologi

Sosiologi merupakan studi yang ilmiah dan objektif mengenai manusia dalam masyarakat, studi mengenai lembaga sosial dan prosesproses sosial. Sosiologi berusaha menjawab pertanyaan mengenai bagaimana masyarakat dimungkinkan, bagaimana cara kerjanya dan mengapa masyarakat itu bertahan hidup (Swingewood dalam Faruk, 2010: 1).

b. Aspek-aspek Sosiologi

Sosiologi merupakan studi yang ilmiah dan objektif mengenai manusia dalam masyarakat, studi mengenai lembaga sosial dan prosesproses sosial. Sosiologi berusaha menjawab pertanyaan mengenai bagaimana masyarakat dimungkinkan, bagaimana cara kerjanya dan mengapa masyarakat itu bertahan hidup. Lewat penelitian yang ketat mengenai lembaga-lembaga sosial, agama, ekonomi, politik, dan keluarga yang secara bersama-sama membentuk apa yang disebut sebagai struktur sosial, sosiologi dikatakan memperoleh gambaran mengenai cara-cara manusia menyesuaikan dirinya dan ditentukan oleh masyarakat-masyarakat tertentu, gambaran mengenai mekanisme sosialisasi, proses belajar secara

\section{Sosiologi Sastra}


kultural, yang dengannya individuindividu dialokasikan pada dan menerima peranan-peranan tertentu dalam struktur sosial itu (Swingewood dalam Faruk, 2010: 1).

\section{METODOLOGI PENELITIAN}

Bentuk penelitian yang digunakan dalam penelitian tentang kajian struktural dan sosiologi sastra dalam novel Petualangan Tom Sawyer karya Mark Twain adalah penelitian deskriptif kualitatif. Metode deskriptif kualitatif adalah sebagai prosedur pemecahan masalah yang diselidiki dengan menggambarkan atau melukiskan keadaan subjek atau objek penelitian. Pada saat sekarang berdasarkan fakta-fakta yang tampak, dengan metode deskriptif kualitatif seorang peneliti sastra dituntut mengungkap fakta-fakta yang tampak atau data dengan cara memberi deskripsi. Bungin (2003: 5) penelitian kualitatif membutuhkan kekuatan analisis yang lebih mendalam, terperinci namun meluas dan holistis, maka kekuatan akal adalah satu-satunya sumber kemampuan analisis dalam seluruh proses penelitian. Penelitian deskriptif kualitatif yang dilakukan diharapkan dapat membantu memperoleh informasi yang akurat dalam penelitian terhadap penelitian tentang kajian struktural dan sosiologis sastra dalam novel Petualangan Tom Sawyer karya Mark Twain.
Subjek penelitian penulis adalah novel berjudul Petualangan Tom Sawyer, cetakan pertama pada Tahun 2007 yang diterbitkan oleh Penerbit Narasi Yogyakarta, dengan tebal 412 halaman. Objek penelitian ini adalah struktur sastra dan aspek sosiologi sastra tokoh utama yang terdapat dalam novel Petualangan Tom Sawyer karya Mark Twain.

Menurut Arikunto (2010: 136), instrumen penelitian adalah alat atau fasilitas yang digunakan oleh peneliti dalam mengumpulkan data agar pekerjaan lebih mudah diolah. Instrumen yang dipakai dalam penelitian ini adalah kertas pencatat data dan alat tulis. Penelitian ini bersifat kualitatif, dengan instrumen utama yaitu penulis dan menggunakan buku-buku acuan tentang teori sastra, teori sosiologi, artikel-artikel dari internet dan novel "Petualangan Tom Sawyer" karya Mark Twain. Dalam pengumpulan data digunakan teknik simak catat. Teknik simak catat adalah suatu cara untuk memperoleh data dengan menggunakan sumber-sumber tertulis (Subroto, 1992: 42). Dalam pengumpulan data penelitian ini menggunakan teknik simak catat, yakni:

1) Membaca novel Petualangan Tom Sawyer karya Mark Twain secara berulang-ulang.

2) Menganalisis aspek struktur sastra novel Petualangan Tom Sawyer Karya Mark Twain. 
3) Menganalisis aspek sosiologi sastra tokoh utama novel Petualangan karya Mark Twain.

Penelitian ini merupakan penelitian kualitatif. Teknik analisis data yang digunakan adalah metode Content Analisys atau teknik menganalisis isi. Disebut juga analisis konten deskriptif adalah metode penelitian yang memanfaatkan seperangkat prosedur untuk menarik kesimpulan yang lebih sahih dari sebuah buku atau dokumen (Weber dalam Haryani, 2009:30) pada novel Petualangan Tom Sawyer karya Mark Twain ini yang digunakan adalah pendekatan analisis sosiologi sastra, yang meliputi aspek moral, aspek etika, aspek sosial ekonomi, aspek cinta kasih, aspek agama dan aspek pendidikan. Langkah-langkah dalam menganalisis data sebagai berikut.

1) Membaca novel berulang-ulang.

2) Mengumpulkan data berupa kutipankutipan langsung maupun tidak langsung yang berhubungan dengan unsur struktur dan sosiologi sastra.

3) Mengklasifikasikan data-data struktur dan sosiologi sastra.

4) Menganalisis data yang telah diklasifikasikan dari membaca dan mencocokkan dari kutipan.

\section{PEMBAHASAN}

\section{Struktur Intrinsik}

a. Tema

Petualangan seorang anak yang mencari kesenangan dan memenuhi keinginannya.

b. Tokoh dan penokohan

Tokoh utama dalam novel Petualangan Tom Sawyer karya Mark Twain adalah Tom Sawyer. Tom Sawyer dalam penokohannya adalah anak yang cerdas, nakal, bandel, dan bisa menghalalkan segala cara untuk memenuhi keinginannya. Huckleberry Finn dalam penokohannya adalah anak yang polos, penurut, dan berpegang teguh jika mempunyai janji. Tokoh tambahan dalam novel Petualangan Tom Sawyer karya Mark Twain adalah Becky Thatcher, Jim, Sid, Bibi Polly, Peter Sburg, Cis, Ben Rogers, Billy fischer, John miller, Joe Harper, Jet Thatcher, Anny Laufence, Marie, Willem, Tuan Walter, Tuan Mayor, Nyonya Dougles, Wille Mufferson, Hopkins, Hol Williams, dan Gernand. Kehadiran tokoh tambahan ini sangat mempengaruhi adegan-adegan yang dilakukan oleh tokoh utama.

c. Alur: Alur campuran

d. Latar atau Setting

Latar atau setting dalam novel Petualangan Tom Sawyer yaitu di kota St. Petersburg, Amerika serikat 
sebagai latar utama, sedangkan latar tambahannya di sungai Misisipi, rumah Bibi polly, rumah nyonya Dougles, hutan, rumah hantu, Jackson island, kuburan, sekolah dan Goa. Dalam hal ini kota St. Petersburg merupakan tempat tinggal tokoh utama. Latar waktu yang terjadi dalam novel Petualangan Tom Sawyer bervariasi, peristiwa yang terjadi bisa kapan saja. Latar sosial dalam novel Petualangan Tom Sawyer adalah petualangan, pendidikam, ajaran moral.

e. gaya bahasa: Hiperbola danPersonifikasi

f. Sudut Pandang: sudut pandang orang ketiga

\section{ASPEK SOSIOLOGI TOKOH UTAMA NOVEL PETUALANGAN TOM SAWYER KARYA MARK TWAIN}

a. Aspek moral

Aspek moral adalah yang terdapat dalam novel Petualangan Tom Sawyer yaitu ketika Tom Sawyer mengakui kesalahannya karena telah berbohong kepada Bibi Polly, bahwa dirinya telah bolos sekolah.

b. Aspek Etika

Dalam novel ini bisa terlihat etika yang di gambarkan Tom Sawyer adalah dia yang berterimakasih kepada Bibi polly yang telah merawatnya dengan penuh belas kasih.

c. Aspek Ekonomi

Aspek ekonomi yang ada dalam novel Petualangan Tom Swyer adalah ketika Tom dan Huckleberry mendapatkan peti harta karun yang berisi uang dan emas yang bisa merubah nasib keduanya. Adapun kutipanya sebagai berikut:

Sampai di kamar itu Tom berkata dengn gembira," Ya,Allah,Huck! Lihatlah!" peti yang di cari-cari itu memmang terleta disana,bersa dengan sebuah peti peluru yang sudah kosong,beberapa ucuk senapan di dalam sarung kulit,dan beberapa perkakas berburu lainnya.

'Barulah dapat!'lata Hauck dengn gembira,sambil meraba raba uang emas itu berulang ulang."Selarang kita menjadi hartawan, Tom!'(halaman: 394).

Keuntungan Tom dan Huck seperti itu sangat menggermparkan seluruh kota. Uang sebanyak itu,apalagi uang emas pula,bagi mereka memmang tidal dapat di nilai. Masing masing bagai kemasukan iblis prilakunya,karena masing masing ingin pula mendapat uang sebnya itu (halaman: 404).

d. Aspek Agama

Dalam novel Petualagan Tom Sawyer, aspek agama biasa terihat ketika Bibi Polly menyuruh Tom 
untuk bersebayang di Gereja pada hari minggu dan setiap minggunya dilakukan beribadah di Gereja. Adapun kutipannya adalah sebagai berikut:

Hari minggu pagi,setelah selesai makan,biasanya bibi polly melakukan perintah agamanya dengan sekalian orang di dalam rumah. Beda dari sembayang,di lihat dari beberapa ayat di dalam kitab. Sesudah iyu Tom dan Sid mesti membaca beberapa ayat yang sudah di tentuka untuk di hapalkan. Beberapa hari sebelum hari minggi,biasanya Sid sudah hapal. Tetapi hari itu Tom baru mulai memaksakan otaknya untuk memghapalkan lima ayat saja,yang sepende pendeknya (halaman: 52).

Setengah sebelas lonceng di bunyikan, warga St.petersburg dengan berkelompok pergi ke greja, akan memenuhi kewajibaya sebagai orang Kristen yang baik. Murid murid sekolah agama tercerai-berai duduknya, karena masing masing mesti berkumpul dengan orangtuanya, supaya bisa di awasinya. Tom di tempatkan di dekat pintu, jauh dari jrndela besar yang terbuka. Karena jendela itu banyak pemandangan keluar (halaman: 71).

e. Aspek pendidikan

Novel Petualangan Tom Sawyer karya

Mark Twain dapat terlihat ketika Tom

berada di sekolah pada saat itu guru yang mengajar sangatlah kejam karena ketika Tom melakukan kesalahan maka iya langsung diberi hukuman jambuka dengan rotan.
Adapun kutipan yang ada di dalam novel adalah sebagai berikut.

Tom menerima hukumanya, yaitu pukulan dengan cambuk beberapa kali. Dengan sabar kemabalilah iya duduk ketempatnya,dan berpikir pikir, boleh jadi timta itu terlumur tidak sengaja karena perbuatanya sendiri. Siapa tau, waktu iya berkejar kejaran dengan kawan-kawannya, tinta itu terlanggar olehnya lalu tumpah isinya kedalam kitab itu. Dengan menghibur hati seperti itu hilanglah segala kesakitan kena cambuk itu (halaman: 257).

\section{SIMPULAN}

Berdasarkan pembahasan yang terdapat pada Kajian Sosiologi Sastra Tokoh utama Novel "Petualangan Tom Sawyer" karya Mark Twain maka peneliti mengambil simpulan sebagai berikut:

Unsur struktural novel Petualangan

Tom Sawyer meliputi tema, tokoh dan penokohan, alur, latar, gaya bahasa dan sudut pandang atau pusat pengisahan. Pengarang mengetahui berbagai hal tentang tokoh, peristiwa, dan tindakan, termasuk motivasi yang melatar belakanginya.

Aspek sosiologi tokoh utama novel Petualangan Tom Sawyer terbagi menjadi lima aspek yaitu: Aspek moral, Aspek moral adalah yang terdapat dalam novel Petualangan Tom Sawyer yaitu ketika Tom Sawyer mengakui kesalahannya karena telah berbohong kepada Bibi Polly, bahwa dirinya 
telah bolos sekolah. Aspek Etika, dalam novel ini bisa terlihat etika yang di gambarkan Tom Sawyer adalah dia yang berterimakasih kepada Bibi polly yang telah merawatnya dengan penuh belas kasih. Aspek Ekonomi, aspek ekonomi yang ada dalam novel Petualangan Tom Swyer adalah ketika Tom dan Huckleberry mendapatkan peti harta karun yang berisi uang dan emas yang bisa merubah nasib keduanya. Aspek Agama, dalam novel Petualagan Tom Sawyer, aspek agama biasa terihat ketika Bibi Polly menyuruh Tom untuk bersebayang di Gereja pada hari minggu dan setiap minggunya dilakukan beribadah di Gereja. Serta aspek pendidikan, novel Petualangan Tom Sawyer karya Mark Twain dapat terlihat ketika Tom berada di sekolah pada saat itu guru yang mengajar sangatlah kejam karena ketika Tom melakukan kesalahan maka iya langsung diberi hukuman cambukan dengan rotan.

\section{DAFTAR PUSTAKA}

Arikunto, Suharsimi. 2010. Prosedur Penelitian Suatu Pendekatan
Praktik. Yogyakarta: Rineka Cipta.

Baribin, Raminah. 1985. Teori dan Apresiasi Prosa Fiksi. Semarang: IKIP Semarang Press.

Bungin, Burhan. 2003. Analisis Data Penelitian Kualitatif. Jakarta: Rajawali Press.

Damono, Sapardi Djoko. 1984. Sosiologi Sebuah Pengantar Ringkas. „Jakarta: Departemen Pendidikan dan Kebudayaan.

Departemen Pendidikan Nasional. 2005. Kamus Besar Bahasa Indonesia. Jakarta: Balai Pustaka.

Endraswara, Suwardi. 2008. Pengantar Pengkajian Sastra. Yogyakarta: Sewon Press.

Faruk. 2010. Pengantar Sosiologi Sastra. Yogyakarta: Pustaka Pelajar.

Mahasiswati, Sari. 2010. "Tinjauan Sosiologi Sastra dalam novel Tretes Tintrim karya Suparto Brata". Skripsi. Purworejo: Universitas Muhammadiyah Purworejo.

Nurgiyantoro, Burhan. 1994. Teori Pengkajian Fiksi. Yogyakarta: Gadjah Mada University Press.

Twain, Mark. 2007. Petualangan Tom

Sawyer. Yogyakarta: Penerbit Narasi. 